\title{
A STUDY OF SEROLOGICAL REACTIONS ASSOCIATED WITH EXPERIMENTAL PLETHORA AND PLETHORIC ANEMIA
}

\author{
By LOUIS A. JULIANELLE AND CARLOS A. PONS \\ (From the Pathological Laboratories of the Philadelphia General Hospital, \\ Philadelphia, Pennsylvania)
}

(Received for publication June 8, 1925)

It has been the uniform experience of investigators studying experimental plethora that plethora can be artificially induced by the transfusion of blood into an homologous animal. After the plethora has reached a maximum, there frequently follows an anemia, sufficiently severe in some cases to cause death. Theories have been offered to explain the mechanism of this blood destruction but the experimental data so far accumulated have not justified a final conclusion.

In order to obtain further data on the mechanism of the blood destruction following plethora, we have undertaken this study. We have employed serological methods in attempting an explanation. Others also have used similar methods in the study of this problem, but in most cases the determinations were not made quantitatively and the results were not uniform. Itami (1) found no hemolysins in the blood of transfused rabbits. Boycott and Douglas (2) (3) also obtained negative results. Ottenberg, Kaliski and Friedman (4) found both agglutinins and hemolysinins in the blood of transfused dogs, and in a subsequent study Ottenberg and Thalheimer (5) demonstrated both of these kinds of antibodies in the blood of transfused cats. Robertson (6) reported the development of agglutinins in rabbits coincident with the development of anemia and Kambe and Komiya (7) found an agglutination titer of $1: 150$ in the blood of a recipient rabbit, while Krumbhaar and Chanutin (8) found neither agglutinins nor hemolysins in their experimental rabbits.

EXPERIMENTAL

In this investigation rabbits were used for transfusions and the donors were not bled more frequently than every fourth day. In 
most instances the recipients received $10 \mathrm{cc}$. of blood each day except Sundays. The blood from the donors was obtained by heart puncture (10 cc. from each animal) and except in a few instances to be mentioned later, the blood was kept from clotting by the addition of sodium citrate. Sufficient blood was obtained for all the transfusions of the day and mixed so that each recipient received pooled blood. Injections were made into the ear vein.

Before beginning transfusions the various bloods were tested for compatability but in no case was incompatability found. This is in accord with the results of Snyder (9). The hematological tests conducted were hemoglobin estimation (Haldane-Newcomer method), red and white blood cell count, reticulocyte count, and white cell differential count. The figures adopted as normal represent an average of three determinations obtained on different days before transfusions. After transfusion, the tests were repeated twice a week. The body weight was determined and serological tests of agglutination and complement fixation were made on the same days.

All the rabbits transfused developed a definite plethora, reaching a maximum in most cases in from 4 to 7 days. In two cases, however, the maximum was delayed until the second week. The degree of plethora varied in the different animals from 30 per cent to almost 100 per cent increase in the number of red cells and from 20 per cent to 50 per cent increase in hemoglobin. After the plethora had reached a maximum degree for the animal studied there occurred a gradual decrease in number of red blood cells and hemoglobin and this in spite of continued transfusions. In certain rabbits the number of red blood cells and percentage of hemoglobin decreased to about normal and remained normal; while in other rabbits the diminution continued until a true anemia developed. During the perod of decrease in numbers of red blood cells and hemoglobin, the number of red blood cells usually showed a decrease before any decrease in hemoglobin became evident. Moreover, the curve representing the decrease in number of red blood cells usually took the form of a straght line; whereas the curve representing the decrease in hemoglobin was steplike. This is well shown in the curve representing these changes in rabbit 1 (fig. 1).

The reticulocyte count showed changes essentially like those first 
demonstrated by Robertson. The number of reticulocytes varied inversely as the number of red cells. As the plethora increased, the reticulocytes decreased, in some instances vanishing entirely. With the appearance of blood destruction, the reticulocytes began to increase, and in plethoric anemia the reticulosis was very marked. This phenomenon was very clearly demonstrated in rabbit 6 (fig. 2).

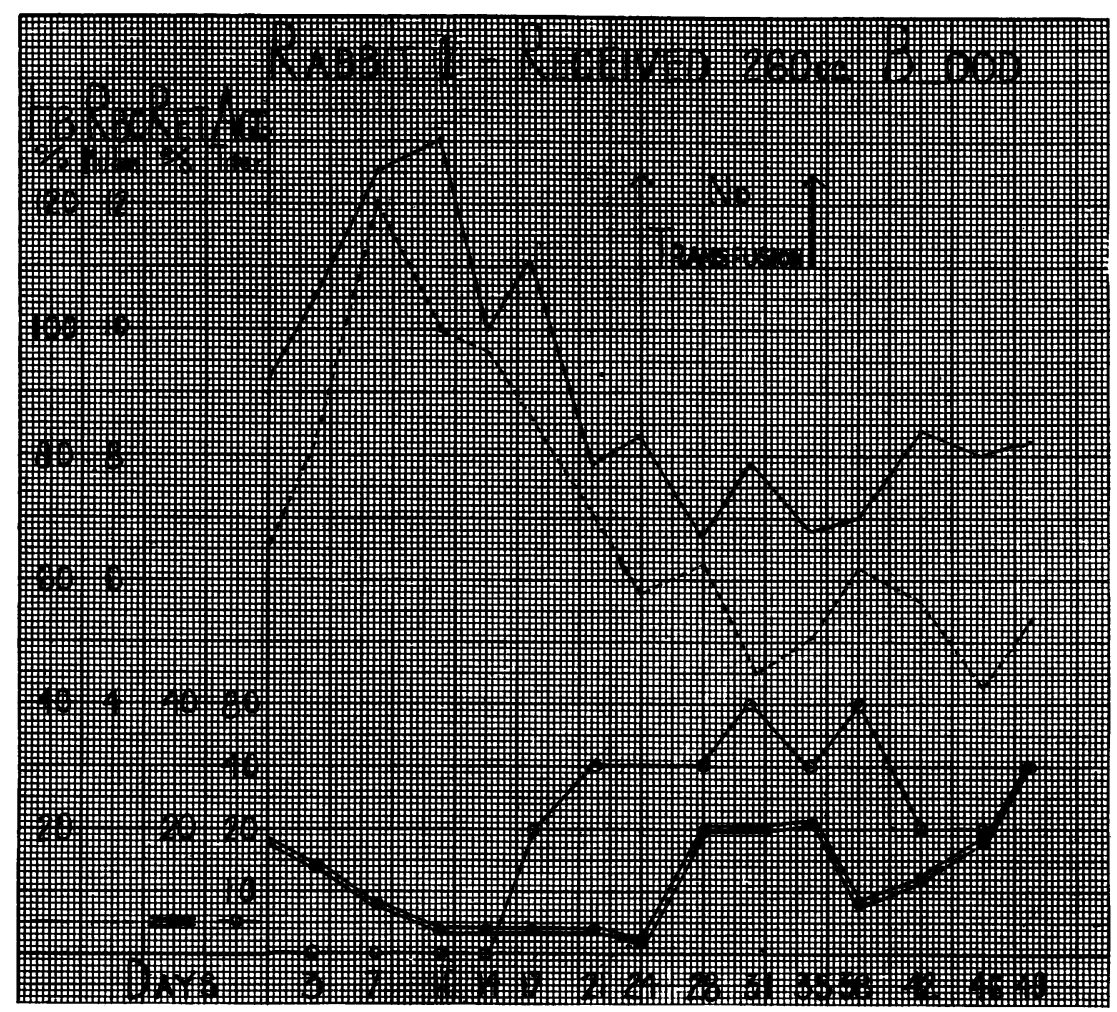

FIG. 1

On the contrary, when no anemia developed, the reticulocytes showed merely the normal variations.

In only two instances did the white blood cells show an increase comparable to that of the red blood cells and hemoglobin. In the other rabbits, the number of leucocytes fluctuated irregularly above and below the normal. 
During plethora the rabbits developed a definite lymphocytosis. With the anemia there was a loss in lymphocytes in favor of the neutrophiles. Otherwise there was a good deal of fluctuation. Occasionally rarer forms of white cells were seen, but they were infrequent.

The body weight showed nothing abnormal. There was a good deal of increase and decrease, but these variations were not considered to

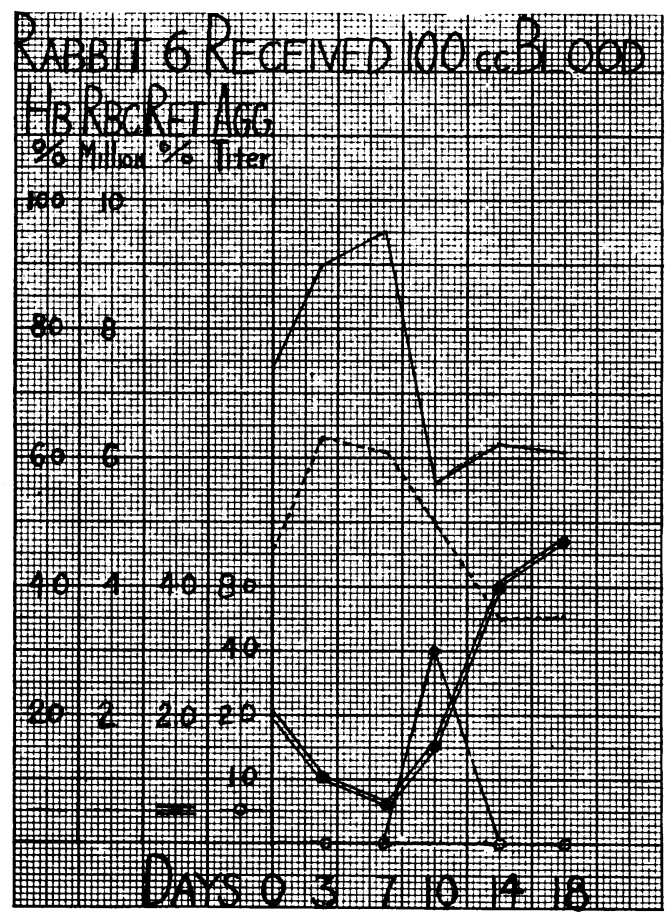

FIG. 2

be of importance. Where the anemia was severe, as in rabbit 6 , the body weight did show a definite gradual decline.

Certain of the rabbits failed to develop a very high degree of plethora and anemia and as it was thought that this might have been due to the transfusion of insufficient quantities of blood, one rabbit was transfused with $20 \mathrm{cc}$. of blood each day, and a second rabbit with 30 cc. of blood each day but the character of the curves representing the blood changes in both these animals do not differ from those rabbits 
receiving $10 \mathrm{cc}$. of blood per day. These two animals showed leucocyte increases commensurate to red blood cell increases.

As it was thought possible that the citrate present in the transfused blood might have an influence on the blood changes, we injected one rabbit daily with $10 \mathrm{cc}$. of blood to which no citrate had been added. This rabbit, however, responded similarly to the other rabbits of this study.

Five of the transfused rabbits died and one was killed and these six rabbits were studied post-mortem.

The spleen usually showed enormous congestion. Microscopically hemosiderin was present in large amounts both intra and extracellulularly. In some cases the congestion was sufficient to obscure the finer details of structure. The endothelial cells showed hyperplasia and the capillaries were loaded with cellular detritus and hemosiderin. An explanation for the lymphocytosis referred to was sought for in changes in the lymph follicles, but these appeared normal.

The bone marrow also showed marked accumulation of hemosiderin. A proliferation of bood cells had taken place and there was an extraordinary dilatation of the capillaries. In three instances an aplastic bone marrow was observed.

The liver showed a high degree of congestion and large quantities of hemosiderin, though neither was so marked as in the spleen and bone marrow. Each liver examined showed a varying degree of cloudy swelling and an intralobular infiltration of small round cells.

The lungs of two of the rabbits showed edema, congestion and partial atelectasis. The kidneys usually showed congestion and formation of casts. In the other organs no changes were observed, or only minor ones.

In an attempt to explain the mechanism of the blood destruction in the recipient rabbits, recourse was taken to a study of the development of iso-immune bodies active against rabbit red blood cells. Determinations were made for the presence of iso-agglutinins and isohemolysins in the blood of the recipient and later in extracts of various organs.

Agglutination tests were conducted using the recipient's sera against specimens of pooled washed red blood cells obtained from the various donors. Occasionally the sera of the recipients was tested against sus- 
pensions of their own red blood cells and also against suspensions of each individual donor's cells. In making the suspensions in all cases the red blood cells were washed free of hemoglobin with saline and then suspended in saline in a 2 per cent concentration. One-half cubiccentimeter each of serum and cells were used. The tests were incubated for one hour at $37^{\circ} \mathrm{C}$. when tentative readings were made. Then they were allowed to stand in the ice chest overnight and a final reading was made on the following morning.

Hemolysin tests were made at the same time that agglutination tests. were conducted. Undiluted recipient serum was tested against the same suspensions of red blood cells used for agglutination determinations. Guinea pig serum diuted 1:20 was used for complement after determining its hemolytic titer. Usually $1 \mathrm{cc}$. of complement was used. Later, the recipient sera were used fresh and also inactivated; and unheated rabbit serum was substituted for the guinea pig complement. The tubes were incubated for one hour at $37^{\circ} \mathrm{C}$. and the readings were made both at the end of this period and on the following morning.

After the serum had been removed from the blood to be tested for the presence of agglutinins and hemolysins, the clot was washed in saline and then broken up in an amount of distilled water equal to that of the serum removed. This mixture was then centrifuged, the supernatant fluid rendered isotonic and used for agglutination and complement fixation determinations. The object of these tests was to determine whether antibodies might have been absorbed in vivo by the recipient's own red blood cells.

Agglutinins were demonstrated in the serum of only half of the recipient rabbits. In these instances, the highest titer was $1: 80$, and their presence was not constant. The appearance of agglutinins coincided with the beginning of blood destruction, but appeared to be in no way related to the degree of blood destruction. Rabbit 6, for example, though severely anemic, did not show as high an agglutinin titer as rabbit 2, in which animal no anemia developed (fig. 3). Similar results were obtained with the clot extracts.

The complement fixation tests were uniformly negative, regardless of the technique employed. This was true not only of the tests with serum, but also with the clot extracts. 
Because of inability to demonstrate hemolysins in vitro, an effort was made to demonstrate their activity in vivo. For this purpose a rabbit was transfused in the usual manner until a plethoric anemia was induced. At this stage $10 \mathrm{cc}$. of blood were withdrawn from this rabbit every other day and transfused into a second rabbit. It was impossible to continue these transfers for more than two weeks, but by that time it was obvious that blood from such a donor produced an

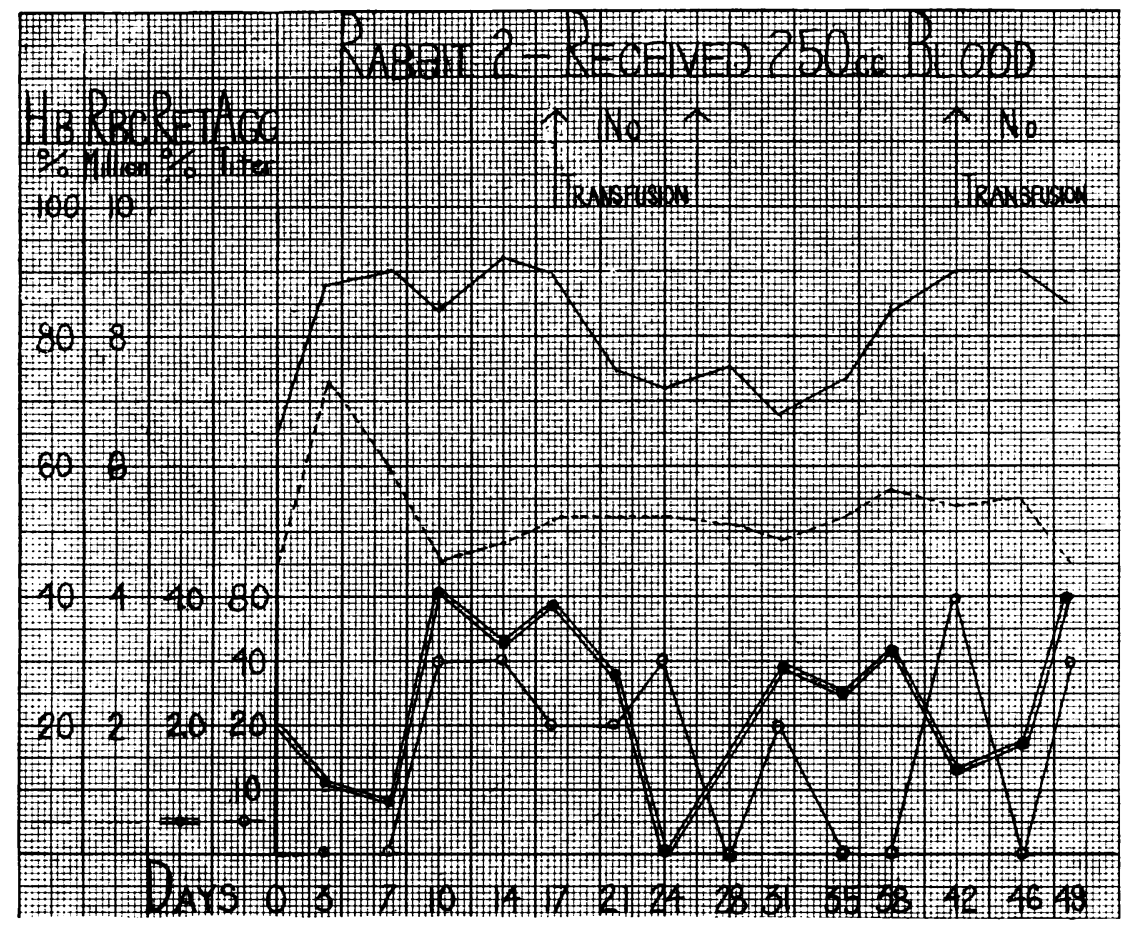

FIG. 3

initial plethora in the recipient animal just as did blood from a normal donor (rabbit 8, fig. 4).

The fixed tissues were then studied for their possible content in antibodies. Keyes (10) showed that in vertebrates red blood cell destruction is normally caused by fixed tissue phagocytes or hemophages. Later the same author (11) showed that a similar mechanism is active in the removal of foreign bodies. Cary (12) reported that 
when foreign red blood cells are introduced into the blood stream, they are removed by hemophages. Motohoshi (13) also showed that rabbits remove foreign red blood cells by the hemophages of the spleen, liver and bone marrow; also that if colloidal silver is administered to animals the hemophages may destroy the animal's own erythrocytes.

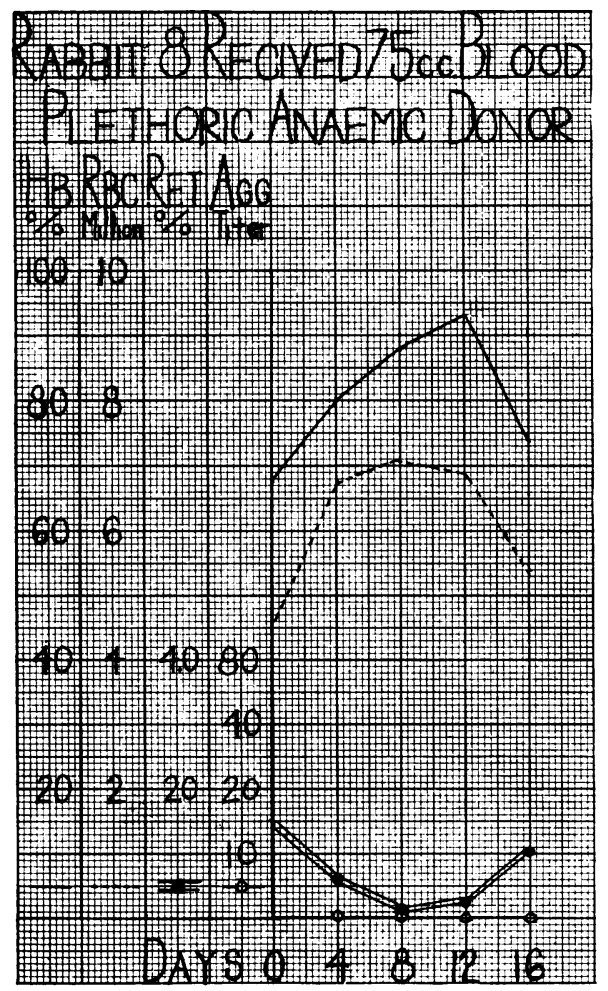

FIG. 4

To determine the part played by fixed tissue immunity the following experiments were conducted. The liver, spleen, bone marrow and blood of transfused rabbits were ground individually in sterile mortars with the addition of small amounts of sterile sand and physiological saline solution. A portion of each of these mixtures was removed and employed for phagocytosis tests as will be described later. The grinding was continued and the material was further diluted about ten 
times with saline. These emulsions were poured into sterile individual flasks and to each was added a few drops of chloroform and enough toluol to make a surface covering. The flasks were incubated for one week at $37^{\circ} \mathrm{C}$. and shaken several times a day. The extracts were then cleared by centrifuging and the supernatant fluid drawn off and tested for the presence of hemolysins and agglutinins. This method is essentially that of Cary's. In all cases the reactions were negative for agglutinins and hemolysins.

The portions first removed for phagocytosis tests were now mixed in capillary pipettes with equal quantities of suspensions of rabbit red blood cells (pooled blood.) The pipettes were sealed and incubated at $37^{\circ} \mathrm{C}$. and samples were removed from the pipettes at the end of 15,30 and 45 minutes, allowed to dry on slides and stained by Wright's stain. It was impossible to find any evidence of phagocytic or hemophagic activity in these preparations.

\section{DISCUSSION}

The chief problem in this investigation has been to explain if possible the mechanism active in the destruction of red blood cells following a plethora induced by repeated transfusions. The possible explanations considered have been $(a)$ that the destruction is due to the development of iso-hemolysins; $(b)$ that the blood destruction may result from increased activity of the hemophages or may be due to the appearance of an increased number of those cells.

As regards the second of these possibilities, no evidence was obtained to indicate that this mechanism is operative. A more thorough investigation was made of the first of these possibilities. It was impossible, however, to demonstrate any hemolytic activity of the serum of the transfused rabbits for mixed rabbit red blood corpuscles obtained from a group of rabbits. In view of certain observations of Ehrlich and Morgenroth and other observers, however, it seemed possible that while there might be found no hemolysins for the mixed cells of a number of rabbits, it might be possible to show that hemolysins active against the corpuscles of certain rabbits comprising a special group might be detected.

In 1900 Ehrlich and Morgenroth (14) reported that in goats following a single intraperitoneal injection of large amounts of goat blood 
isohemolysins appeared but those were never active against the goats' own cells but were only active against the red blood cells of certain other goats. The authors concluded therefore that goats have potential hematological groupings which become real only under certain conditions of which their experiment supplied one, and these groupings therefore differ from those present in man where the groupings do not require any special stimulus in order to make them evident.

Hada and Rosenthal (15) in the case of chickens, Ottenberg, Kaliski and Friedman in dogs, Ottenberg and Thalheimer in cats with analogous methods were able to produce isohemolysins which, like the isohemolysins of Ehrlich and Morgenroth, were active against cells of certain individuals only. That a similar condition might be present in rabbits and that this might be related to the form of blood destruction being studied, the sera of the transfused rabbits were tested against suspensions of cells from a number of individual donors. Again, however, no hemolytic property of the sera could be detected.

In the sera of certain of the transfused animals moderate grades of agglutinating power for rabbit cells were found but cells from all donors were equally well agglutinated. In any case it is difficult to bring this property of agglutination into any causal relationship with the blood destruction.

Our experiments, therefore, do not supply any evidence suggesting a potential hematological grouping in rabbits and do not indicate that the appearance of iso-hemolysins in the blood of transfused rabbits is responsible for the blood destruction.

That antibodies might be formed by the fixed tissue cells and yet not be detected in the blood is still a possibility. Either all the antibodies might be fixed by the transfused corpuscles or the methods might not be delicate enough to detect the excess of antibodies present. If the former were the difficulty, it might be possible that antibodies could be detected if the tests were made only after a sufficient time were allowed to elapse following the last transfusion for all the foreign cells to be disposed of. This expedient yielded no different results, however. It is still possible that the rabbits' own red blood cells as well as those injected might bind the antibodies. To test this possibility an attempt was made to disrupt any possible union of antibody with the rabbit's own cells by extraction of the cells with water. This 
procedure, however, also yielded only negative results. Finally, an attempt was made to detect whether antibodies were fixed to the tissue cells. With the methods employed no hemolytic antibodies were found.

\section{SUMMARY AND CONCLUSIONS}

1. Rabbits have been repeatedly transfused with rabbit blood. Plethora followed the transfusions and this in turn was followed by blood destruction.

2. The reticulocytes tended to decrease and in some cases to disappear with the plethora; but with beginning blood destruction, there was a rise in reticulocytes.

3. Leucocyte counts apparently bore no relation to the transfusions. The lymphocytes usually increased with plethora and decreased after a normal or anemic condition developed.

4. The striking feature of the pathology was the enormous deposition of hemosiderin in spleen, bone marrow, and liver. This was found both within phagocytes and extracellular.

5. Various hypotheses to explain the blood destruction following experimental plethora were tested by a number of methods. No evidence was obtained that the blood destruction is the result of the development of iso-hemolysins. No evidence was obtained to show that this result is due to greater activity of hemophages.

6. A number of facts concerning the blood changes occurring following transfusions have been obtained, but the explanation of postplethoric anemia must await further work.

\section{BIBLIOGRAPHY}

1. Itami: Folia haemotol, 1908, vi, 425.

2. Boycott and Douglas: Jour. Path. and Bact., 1908-09, xiii, 414.

3. Boycott and Douglas: Jour. Path. and Bact., 1909-10, xiv, 294.

4. Ottenberg, Kaliski and Friedman: Jour. Med. Res., 1913, xxviii, 141.

5. Ottenberg and Thalheimer: Jour. Med. Res., 1915, liii, 213.

6. Robertson: Jour. Exp. Med., 1917, xxvi, 221.

7. Kambe and Komiya: Amer. Jour. Physiol., 1920, liii, 1.

8. Krumbhaar and Chanutin: Jour. Exp. Med., 1922, xxxv, 847.

9. Snyder, L. H.: Jour. Immunol., 1924, ix, 45-48.

10. Keyes: Intern. Monat. f. Anat. und Phys., 1914, xxxi, 543. 
11. Keyes: Jour. Inf. Dis., 1915, xvii, 432.

12. Cary: Jour. Med. Res., 1922, xliii, 399.

13. Motohoshi: Jour. Med. Res., 1923, xliii, 419.

14. Ehrlich and Morgenroth: Ber. Klin. Woch., 1900, xxi, 453.

15. Rosenthal and Hada: Zeitschr. f. Imm., 1913, xvi, 524. 